\title{
Search for envelopes of some stellar planetary nebulae, symbiotic stars and further emission-line objects ${ }^{\star}$
}

\author{
L. Kohoutek \\ Hamburger Sternwarte, Gojenbergsweg 112, D-21029 Hamburg, Germany
}

Received January 6; accepted January 25, 1997

\begin{abstract}
At 17 emission-line objects, mainly PN, the seeing disc has been compared with that of some surrounding stars (CCD frames taken through $B, V, R$, [OIII] $5007 \AA$ and $\mathrm{H} \alpha$ filters). Nebulosities were found at: $\mathrm{CPD}-53^{\circ} 8315\left(0^{\prime \prime} .5\right.$ in $x$-direction, $0^{\prime \prime} .4$ in $y$-direction), H $2-2\left(0^{\prime \prime} 3,1^{\prime \prime} .4\right)$ and CPD $-56^{\circ} 8032\left(1^{\prime \prime} .3,1^{\prime \prime} 3\right)$. Further small nebulosities are possible at MWC 560, MWC 574, LS IV $-12^{\circ} 111$ and HR Del, but they should be considered as rather uncertain. Besides, the known outer nebula at CPD - 53 ${ }^{\circ} 8315$ (2 condensations, 11'.6 separation, $\mathrm{PA}=146^{\circ}$ ) was observed, and the author discovered a circular halo of $50^{\prime \prime}$ around $\mathrm{Hb} 6$ - both outer nebulosities visible in the light of $\mathrm{H} \alpha$.
\end{abstract}

Key words: planetary nebulae: general; stars: symbiotic; stars: novae; stars: horizontal branch

\section{Introduction}

There are many emission-line objects classified as planetary nebulae $(\mathrm{PN})$ which are of stellar appearance. Assuming that this classification is correct, such objects have to be either young PN with very small nebulae, or old PN with large nebulae, which are very faint and so far invisible. It would be very important from the evolutionary point of view to differentiate between these two possibilities.

Besides, there are 43 emission-line objects which appear simultaneously in the catalogues of planetary nebulae as well as in the catalogues of symbiotic stars (SS; see Allen 1984). The variability and the presence of a red component do not seem to be sufficient criteria for distinguishing both cases. In spite of the fact that the origin and the early evolution of $\mathrm{PN}$ is little known, the knowledge of

\footnotetext{
Send offprint requests to: L. Kohoutek

* Based on observations collected at the European Southern Observatory at La Silla, Chile.
}

the existence of nebulae can help to classify such objects better than in the past.

This is the first series of objects the choice of which (Table 1) was made mainly with regard to the above circumstances.

\section{Observations}

The observations were made with the telescope $0.9 \mathrm{~m}$ Dutch + CCD in April/May 1995 at La Silla, Chile (European Southern Observatory). We used the following systems or interference filters:

\begin{tabular}{llll}
$\begin{array}{l}\text { System/ } \\
\text { filter }\end{array}$ & ESO No. & $\begin{array}{l}\text { Peak } \\
\text { wavelength }\end{array}$ & $\begin{array}{l}\text { Band- } \\
\text { width }\end{array}$ \\
\hline & & $\mathrm{nm}$ & $\mathrm{nm}$ \\
$B$ & 419 & 438.4 & 101.9 \\
$V$ & 420 & 529.3 & 116.9 \\
$R$ & 421 & 599.4 & 163.8 \\
{$[\mathrm{OIII}]$} & 688 & 500.5 & 5.7 \\
$\left.\mathrm{H} \alpha^{*}\right)$ & 387 & 654.6 & 8.1
\end{tabular}

*) + [NII] em.-lines at 6548 and very little at $6584 \AA$.

We made both long integrated frames in order to find faint outer envelopes (haloes), and short integrations with the aim of comparing $F W H M$ in $x$ and $y$ directions of the object with those of surrounding stars in order to find small envelopes. The list of observed objects is given in Table 1. We observed 17 objects, mainly proto-PN and stellar PN (11 objects), but also some symbiotic stars, emission-line stars and old novae. The small planetary nebulae $\mathrm{Hb} 6$ and IC 4997 were observed for comparison. The remark "paper" in this table means that a separate paper is being planned on the respective object.

For the programme objects we give in Table 2 the list of individual frames (altogether 119) with the respective $F W H M$ in both directions as well as $F W H M$ of stars in the vicinity ( $n$ is the number of stars used, total $n=737$ ). The mean value of $F W H M$ for stars is $1^{\prime \prime} 62$ and $1^{\prime \prime} .58$ in the $x$ and $y$ direction, respectively. These values represent mainly the seeing images together with the instrumental 
Table 1. List of objects

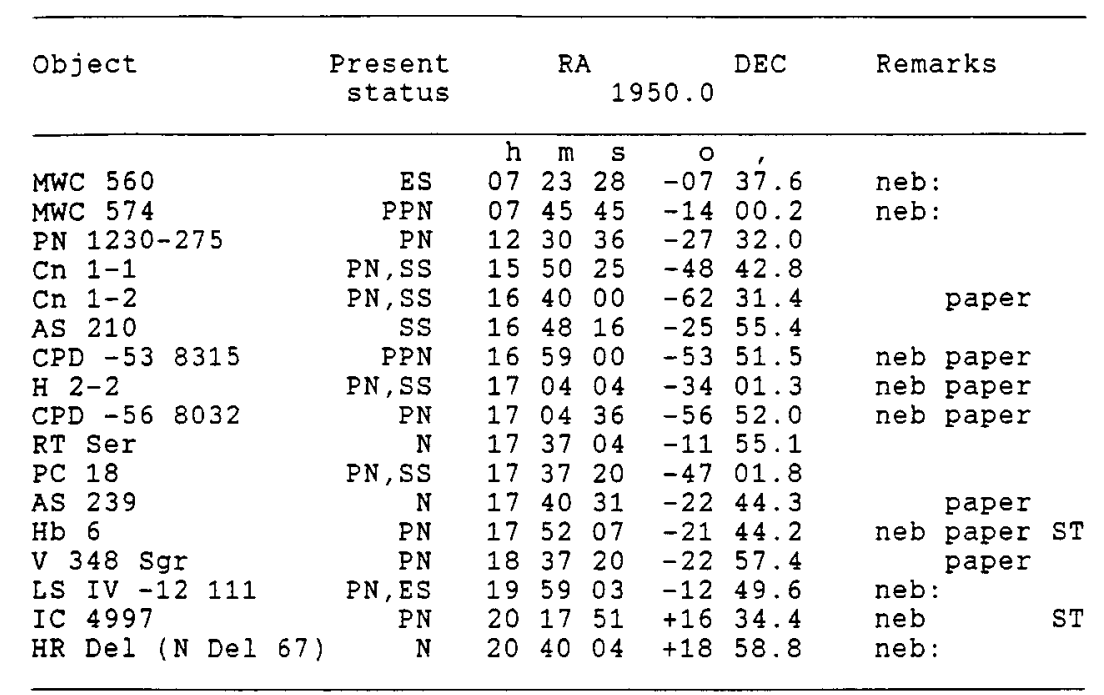

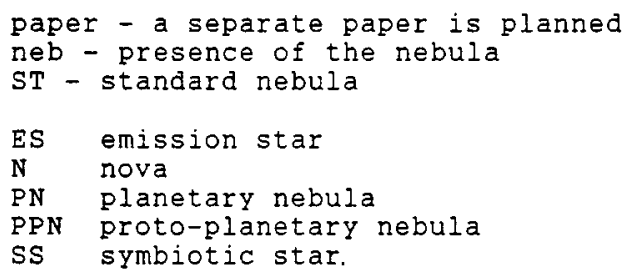

images combined with the focus inaccuracy and the guiding error. The last error is probably negligible because of nearly identical $F W H M$ values in both directions. The integration time was $0.3-720 \mathrm{~s}$, but for longer than about $180 \mathrm{~s}$ the autoguider was used. The studied objects were sometimes overexposed (10 frames) on the long integrated frames.

\section{Results}

The recognition of the nebula was defined in case the $F W H M$ value of the object exceeded that of the stars by 1 sigma $=00^{\prime \prime} 06$ in at least one direction. This happened with $\mathrm{CPD}-53^{\circ} 8315, \mathrm{H} 2-2$ and $\mathrm{CPD}-56^{\circ} 8032$ beside the standard nebulae $\mathrm{Hb} 6$ and IC 4997. The following further objects have larger $F W H M$ values compared with those of the stars in the vicinity, being close to 0.'06: MWC 560, MWC 574, LS IV $-12^{\circ} 111$ and HR Del. The existence of small nebulae at these objects is therefore possible.

For the calculation of the nebular diameter the simple relation

$F W H M^{2}($ nebula $)=F W H M^{2}($ object $)-F W H M^{2}($ stars $)$

was used. The results are given in Table 3 for reliable and possible nebulae. We summarized the diameters in $x$ and $y$ direction, respectively, together with the mean errors, for which $N$ - number of frames (see Table 2) - was used.

\section{Discussion of individual objects}

4.1. $C P D-53^{\circ} 8315(P K 334-07.1)$

This object (He $3-1312$ ) was classified as possible protoPN in Supplement 1 (Kohoutek 1978) to CGPN (Perek \& Kohoutek 1967) and included among PN in Supplement 4 to CGPN (Kohoutek 1993). It appears in SECGPN (Acker et al. 1992) as SaSt $2-12$, PN G 334.8 - 07.4. There it is of stellar diameter, but recently Schwarz et al. (1992) found two condensations visible through $\mathrm{H} \alpha+[\mathrm{NII}]$ filter (and not visible through [OIII] $5007 \AA$ filter) having a separation of about 12 arcsec and lying symmetrical to the centre (to the star). We confirm this observation (Fig. 1) and present the picture of this nebula showing the central object and two condensations. May be the condensations (Table 3) are part of a faint outer envelope. The higher brightness in the vicinity of the star may also be an instrumental reflection. The nature of this "faint nebulosity" near the star cannot be recognized according to our frames.

Besides, CPD $-53^{\circ} 8315$ belongs to objects where the image is larger than those of stars, which fact we interpret with the presence of a nebulosity. This inner nebula of about $0.5 \times 0.4$ arcsec is very small, but reliable as we hope; its diameter is nearly the same in $\mathrm{H} \alpha$ (4 frames) and in [OIII] $5007 \AA$ (2 frames). 
Table 2. Observed images

\begin{tabular}{|c|c|c|c|c|c|c|c|c|}
\hline object & Frame & & $\begin{array}{l}\text { exp } \\
{[\sec ]}\end{array}$ & $\begin{array}{c}\text { FWHM } \\
\quad X\end{array}$ & $\underset{Y}{\text { stars }}$ & $n$ & $\underset{X}{\text { FWHM }} \stackrel{0}{ }$ & $\underset{\boldsymbol{Y}}{\mathrm{object}}$ \\
\hline MWC 560 & $\begin{array}{l}546 \\
547 \\
548 \_s \\
541 \\
544 \\
540 \\
543 \\
542 \\
545\end{array}$ & $\begin{array}{l}\mathrm{Ha} \\
\mathrm{Ha} \\
\mathrm{Ha} \\
\mathrm{V} \\
\mathrm{V} \\
\mathrm{B} \\
\mathrm{B} \\
\mathrm{R} \\
\mathrm{R}\end{array}$ & $\begin{array}{r}30 \\
30 \\
600 \\
15 \\
15 \\
10 \\
10 \\
7 \\
7\end{array}$ & $\begin{array}{l}2.30 \\
2.03 \\
1.75 \\
2.07 \\
2.13 \\
2.07 \\
2.20 \\
2.01 \\
1.70\end{array}$ & $\begin{array}{l}1.63 \\
1.55 \\
2.08 \\
1.63 \\
1.71 \\
1.74 \\
1.92 \\
1.57 \\
1.45\end{array}$ & $\begin{array}{l}4 \\
5 \\
6 \\
9 \\
8 \\
8 \\
8 \\
8 \\
7\end{array}$ & $\begin{array}{l}2.48 \\
2.06 \\
\text { overex } \\
2.15 \\
2.21 \\
2.01 \\
2.30 \\
2.02 \\
1.77\end{array}$ & $\begin{array}{l}1.74 \\
1.60 \\
\times 1 . \\
1.60 \\
1.73 \\
1.71 \\
1.97 \\
1.64 \\
1.52\end{array}$ \\
\hline MWC 574 & $\begin{array}{l}730 \\
731 \\
732 \_s\end{array}$ & $\begin{array}{l}\mathrm{Ha} \\
\mathrm{Ha} \\
\mathrm{Ha}\end{array}$ & $\begin{array}{r}30 \\
240 \\
600\end{array}$ & $\begin{array}{l}2.12 \\
1.88 \\
1.65\end{array}$ & $\begin{array}{l}1.63 \\
1.58 \\
1.65\end{array}$ & $\begin{array}{l}5 \\
7 \\
6\end{array}$ & $\begin{array}{l}2.27 \\
1.89 \\
\text { overex }\end{array}$ & $\begin{array}{l}1.77 \\
1.61 \\
\mathrm{xp} .\end{array}$ \\
\hline PN $1230-275$ & $\begin{array}{l}096 \\
094 \\
095\end{array}$ & $\begin{array}{l}\mathrm{Ha} \\
{[\mathrm{OIII}]} \\
{[\mathrm{OIII}]}\end{array}$ & $\begin{array}{r}720 \\
60 \\
600\end{array}$ & $\begin{array}{l}1.13 \\
1.38 \\
1.32\end{array}$ & $\begin{array}{l}1.12 \\
2.01 \\
1.73\end{array}$ & $\begin{array}{l}6 \\
4 \\
5\end{array}$ & $\begin{array}{l}1.12 \\
1.40 \\
1.28\end{array}$ & $\begin{array}{l}1.08 \\
1.92 \\
1.68\end{array}$ \\
\hline Cn 1-1 & $\begin{array}{l}836 \\
837 \\
838 \_s \\
839 \\
840\end{array}$ & $\begin{array}{l}\mathrm{Ha} \\
\mathrm{Ha} \\
\mathrm{Ha} \\
{[\text { OI I I ] }} \\
\text { [OIII] }\end{array}$ & $\begin{array}{r}20 \\
60 \\
600 \\
60 \\
480\end{array}$ & $\begin{array}{l}1.91 \\
1.60 \\
1.64 \\
1.95 \\
1.58\end{array}$ & $\begin{array}{l}1.22 \\
1.39 \\
1.37 \\
1.52 \\
1.64\end{array}$ & $\begin{array}{l}6 \\
6 \\
6 \\
5 \\
6\end{array}$ & $\begin{array}{l}1.96 \\
1.66 \\
\text { overex } \\
1.97 \\
\text { overex }\end{array}$ & $\begin{array}{l}1.28 \\
1.41 \\
x p . \\
1.53 \\
x p .\end{array}$ \\
\hline $\operatorname{Cn} 1-2$ & $\begin{array}{l}126 \\
127 \\
124 \leq s \\
125\end{array}$ & $\begin{array}{l}\mathrm{Ha} \\
\mathrm{Ha} \\
{[O I I I]} \\
\text { [OIII] }\end{array}$ & $\begin{array}{r}30 \\
360 \\
30 \\
720\end{array}$ & $\begin{array}{l}2.19 \\
2.17 \\
2.17 \\
3.42\end{array}$ & $\begin{array}{l}1.56 \\
1.52 \\
2.42 \\
2.71\end{array}$ & $\begin{array}{l}6 \\
5 \\
6 \\
6\end{array}$ & $\begin{array}{l}2.19 \\
\text { overex } \\
2.15 \\
3.40\end{array}$ & $\begin{array}{l}1.57 \\
\times \mathrm{p} . \\
2.48 \\
2.72\end{array}$ \\
\hline AS 210 & $\begin{array}{l}627 \\
628 \_s \\
444 \\
445 \\
441 \\
442 \\
443\end{array}$ & $\begin{array}{l}\mathrm{Ha} \\
\mathrm{Ha} \\
{[\mathrm{O} I I I]} \\
{[O I I I]} \\
\mathrm{V} \\
\mathrm{B} \\
\mathrm{R}\end{array}$ & $\begin{array}{r}30 \\
600 \\
60 \\
720 \\
10 \\
15 \\
7\end{array}$ & $\begin{array}{l}1.76 \\
1.34 \\
1.84 \\
1.92 \\
1.65 \\
2.06 \\
1.61\end{array}$ & $\begin{array}{l}1.31 \\
1.39 \\
1.69 \\
1.76 \\
1.59 \\
2.00 \\
1.67\end{array}$ & $\begin{array}{l}6 \\
6 \\
6 \\
8 \\
6 \\
6 \\
6\end{array}$ & $\begin{array}{l}1.81 \\
\text { overex } \\
1.92 \\
1.95 \\
1.65 \\
2.14 \\
1.61\end{array}$ & $\begin{array}{l}1.27 \\
x p . \\
1.68 \\
1.76 \\
1.55 \\
2.00 \\
1.64\end{array}$ \\
\hline CPD-53 8315 & $\begin{array}{l}633 \\
635 \_s \\
636 \\
637 \\
638 \\
446 \\
639 \_s\end{array}$ & $\begin{array}{l}\mathrm{Ha} \\
\mathrm{Ha} \\
\mathrm{Ha} \\
\mathrm{Ha} \\
\mathrm{Ha} \\
\text { [OIII] } \\
\text { [OIII] }\end{array}$ & $\begin{array}{r}20 \\
30 \\
600 \\
90 \\
60 \\
60 \\
90\end{array}$ & $\begin{array}{l}1.35 \\
1.31 \\
1.60 \\
1.60 \\
1.61 \\
1.89 \\
1.80\end{array}$ & $\begin{array}{l}1.39 \\
1.35 \\
1.63 \\
1.56 \\
1.52 \\
1.64 \\
1.84\end{array}$ & $\begin{array}{l}5 \\
4 \\
8 \\
4 \\
5 \\
3 \\
4\end{array}$ & $\begin{array}{l}1.45 \\
1.40 \\
\text { overex } \\
1.67 \\
1.68 \\
1.95 \\
1.85\end{array}$ & $\begin{array}{l}1.46 \\
1.43 \\
\times P . \\
1.57 \\
1.54 \\
1.73 \\
1.86\end{array}$ \\
\hline H $2-2$ & $\begin{array}{l}128 \\
129 \\
130 \_s \\
131 \\
132\end{array}$ & $\begin{array}{l}\mathrm{Ha} \\
\mathrm{Ha} \\
\mathrm{Ha} \\
{[\mathrm{OIII}]} \\
{[\mathrm{OIII}]}\end{array}$ & $\begin{array}{r}30 \\
30 \\
360 \\
60 \\
720\end{array}$ & $\begin{array}{l}2.05 \\
1.98 \\
2.05 \\
1.40 \\
1.59\end{array}$ & $\begin{array}{l}1.25 \\
1.26 \\
1.37 \\
1.78 \\
2.14\end{array}$ & $\begin{array}{l}6 \\
6 \\
6 \\
6 \\
6\end{array}$ & $\begin{array}{l}2.09 \\
2.01 \\
\text { overex } \\
1.40 \\
1.67\end{array}$ & $\begin{array}{r}1.24 \\
1.23 \\
\times p . \\
2.13 \\
2.63\end{array}$ \\
\hline CPD-56 8032 & $\begin{array}{l}640 \\
641 \\
642 \\
644 \\
645 \\
448 \\
449 \\
450 \\
265 \\
267 \\
268 \\
269 \\
270 \\
271 \\
272 \\
273\end{array}$ & $\begin{array}{l}\mathrm{Ha} \\
\mathrm{Ha} \\
\mathrm{Ha} \\
\mathrm{Ha} \\
\mathrm{Ha} \\
\text { [OIII] } \\
\text { [OIII] } \\
{[\text { OIII] }} \\
\mathrm{V} \\
\mathrm{V} \\
\mathrm{V} \\
\mathrm{V} \\
\mathrm{V} \\
\mathrm{V} \\
\mathrm{V} \\
\mathrm{V}\end{array}$ & $\begin{array}{r}30 \\
60 \\
5 \\
600 \\
240 \\
60 \\
60 \\
720 \\
20 \\
10 \\
10 \\
10 \\
10 \\
10 \\
10 \\
2\end{array}$ & $\begin{array}{l}1.54 \\
1.60 \\
1.43 \\
2.18 \\
1.60 \\
1.83 \\
1.95 \\
1.82 \\
1.33 \\
1.12 \\
1.29 \\
1.31 \\
1.34 \\
1.18 \\
1.21 \\
1.13\end{array}$ & $\begin{array}{l}1.53 \\
1.67 \\
1.50 \\
1.90 \\
1.61 \\
1.70 \\
1.85 \\
1.75 \\
1.40 \\
1.40 \\
1.53 \\
1.65 \\
1.45 \\
1.38 \\
1.34 \\
1.47\end{array}$ & $\begin{array}{l}8 \\
8 \\
8 \\
8 \\
8 \\
6 \\
7 \\
7 \\
7 \\
7 \\
6 \\
6 \\
6 \\
6 \\
7 \\
6\end{array}$ & $\begin{array}{l}2.07 \\
2.02 \\
1.92 \\
2.49 \\
2.03 \\
2.37 \\
2.36 \\
2.29 \\
1.85 \\
1.67 \\
1.80 \\
1.80 \\
1.86 \\
1.71 \\
1.71 \\
1.68\end{array}$ & $\begin{array}{l}2.10 \\
2.14 \\
1.97 \\
2.33 \\
2.07 \\
2.20 \\
2.27 \\
2.18 \\
1.81 \\
1.88 \\
1.98 \\
2.06 \\
1.88 \\
1.85 \\
1.78 \\
1.90\end{array}$ \\
\hline
\end{tabular}


Table 2. continued

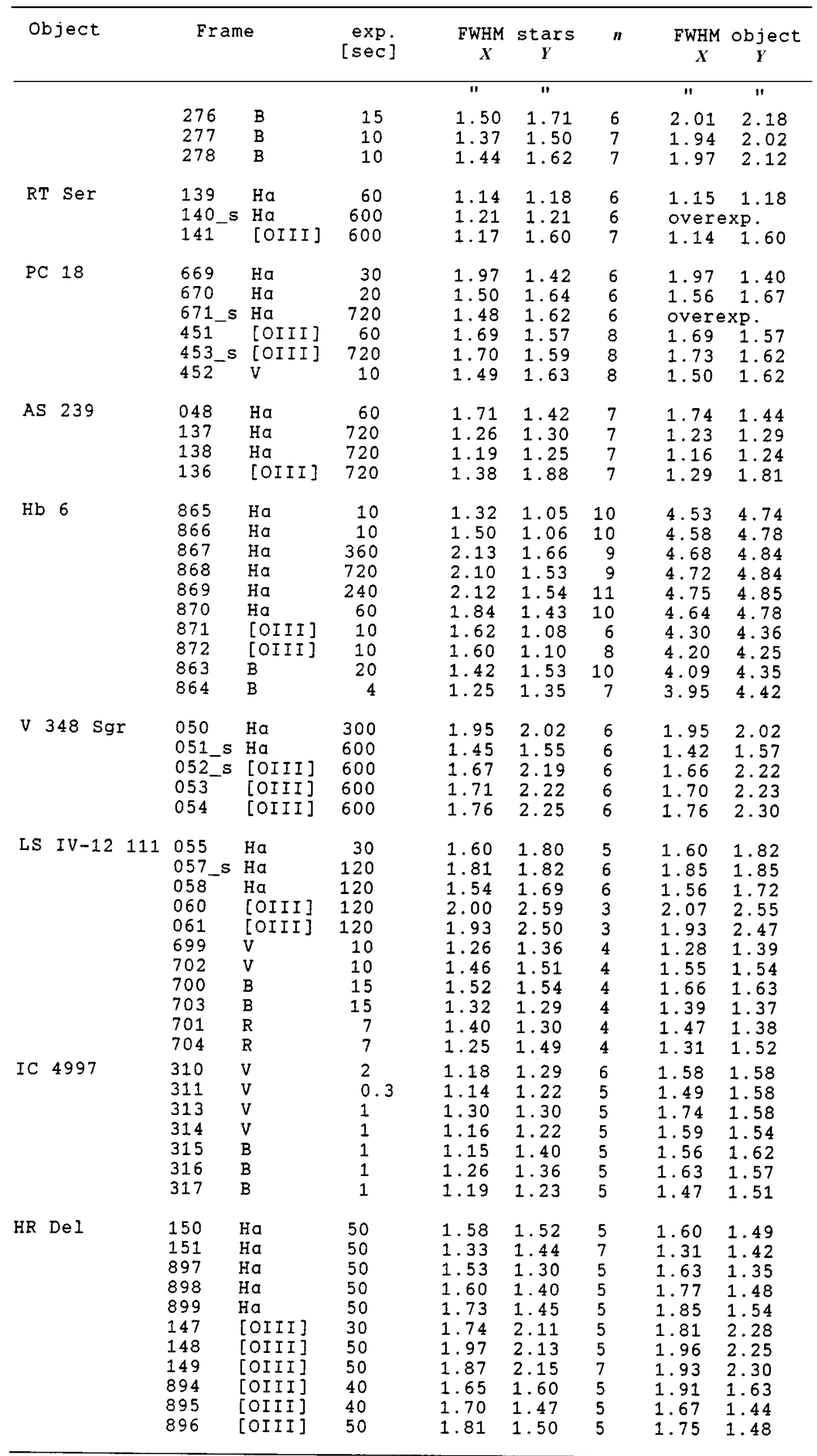


Table 3. Nebular diameters

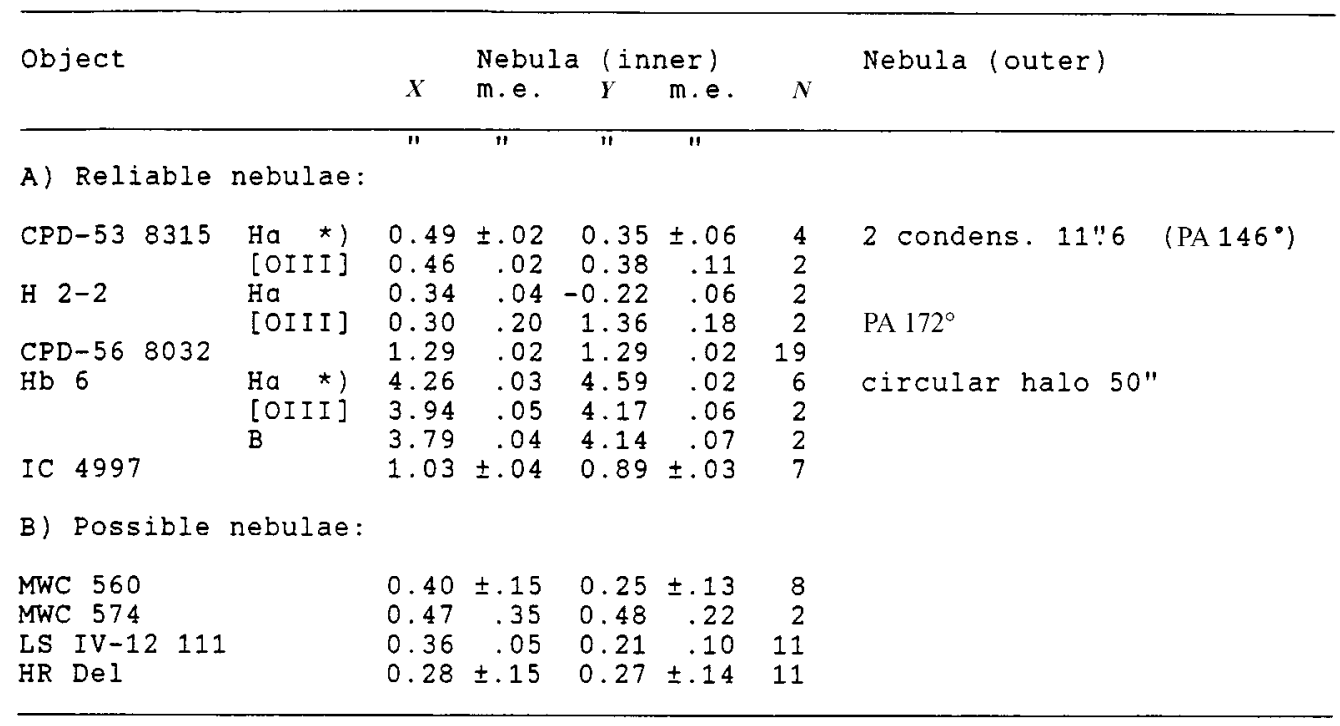

*) see text (Sect. 4 ).

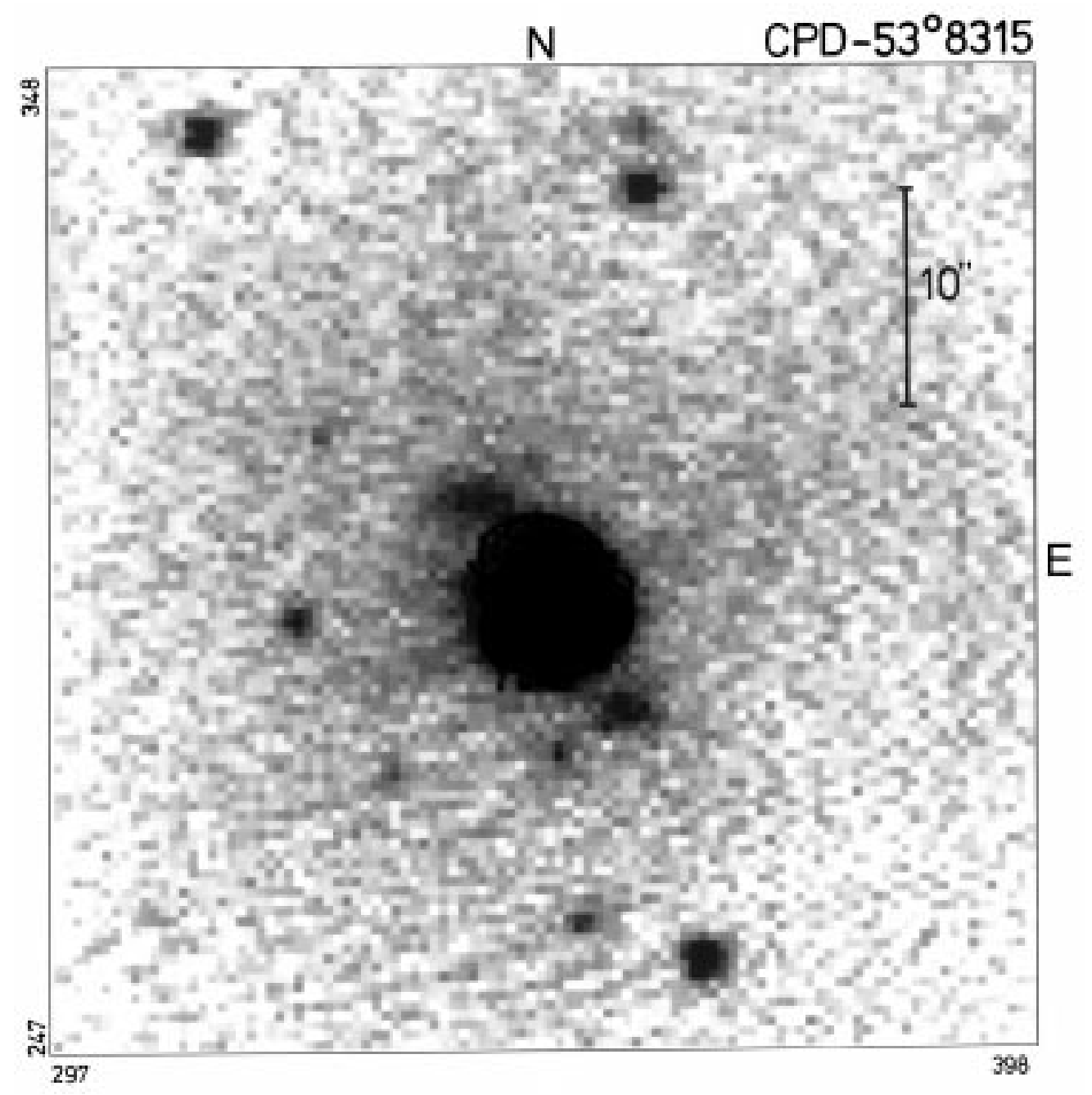

Fig. 1. $\mathrm{CPD}-53^{\circ} 8315$ in the light of $\mathrm{H} \alpha$ with two condensations $11^{\prime \prime} 6$ (PA $146^{\circ}$ ) apart; exp. $30 \mathrm{~s}$ 


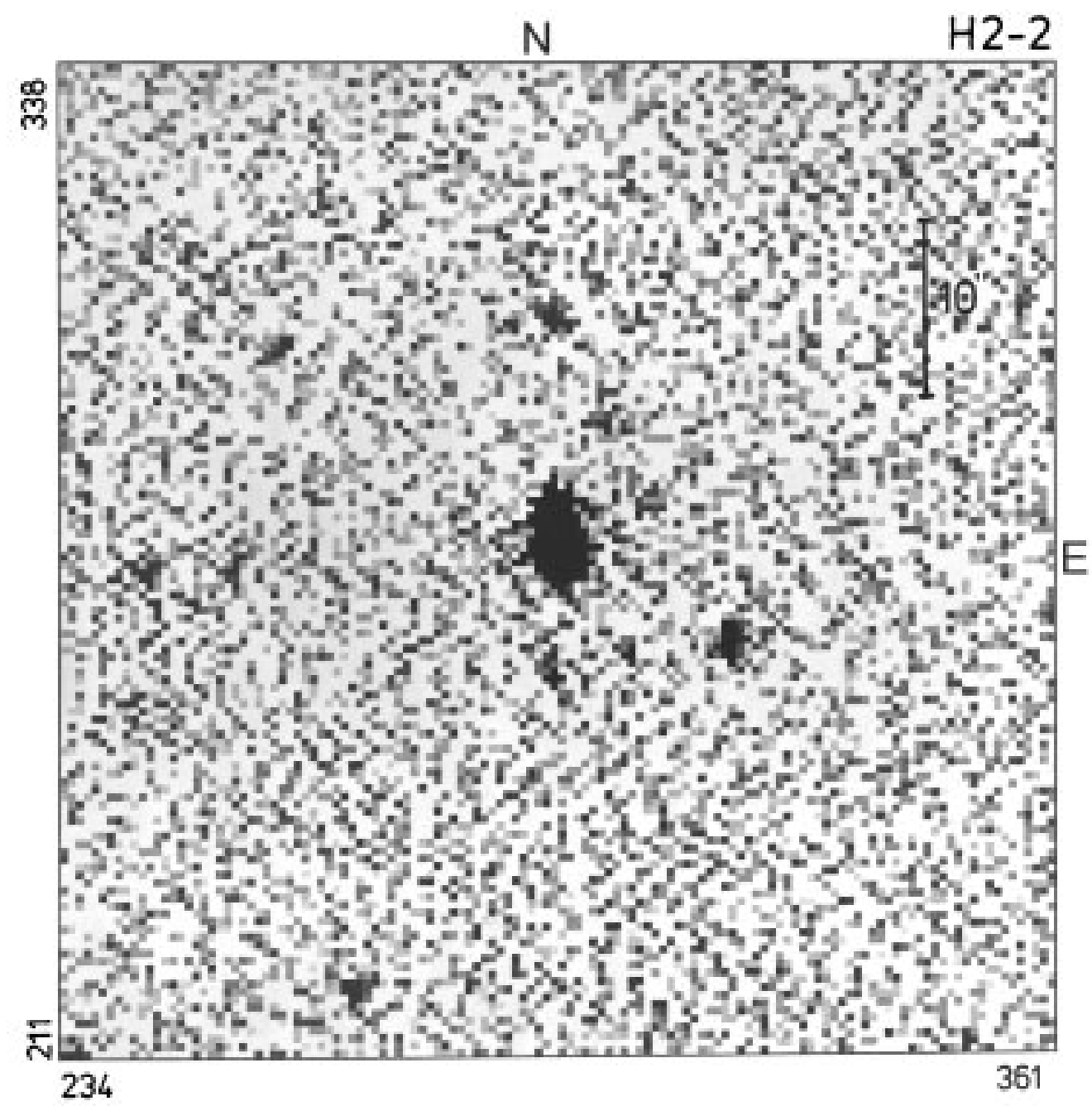

Fig. 2. $\mathrm{H} 2-2$ in the light of [OIII] $5007 \AA$ elongated in PA $172^{\circ}$; exp. $60 \mathrm{~s}$

\section{2. $H 2-2(P K 351+03.1)$}

Rejected from SECGPN as symbiotic star. Our frames show $\mathrm{H} 2-2$ stellar in $\mathrm{H} \alpha$, but elongated in $y$ direction in [OIII] $5007 \AA\left(1.4 \operatorname{arcsec}, \mathrm{PA}\right.$ about $\left.172^{\circ}\right)$, which may be caused by condensations or loops (Fig. 2).

\section{3. $C P D-56^{\circ} 8032(P K 332-9.1)$}

Included among PN in Supplement 5 to CGPN (Kohoutek 1996). It appears in SECGPN as He $3-1333$, PN G $332.9-09.9$, stellar appearance. Small optical nebulosity of $1.3 \times 1.2 \mathrm{arcsec}, \mathrm{PA} 10^{\circ}$, was found (Kohoutek 1995) as well as its being nearly identical with the speckle infrared observations of dust emission features at $3.28 \mu \mathrm{m}$ (Roche et al. 1986). This optical nebulosity was now confirmed using all existing frames.

\section{4. $H b 6(P K 7+01.1)$}

In SECGPN under 007.2+01.8; optical diameter 5 arcsec from Cahn \& Kaler (1971). The variability of this object (= AS Sgr) is probably of instrumental origin (Arhipova 1973), the central star is unknown. Hb 6 has been chosen as a standard nebula in order to compare our measured dimension with that given in the literature. The derived nebular diameter (see Table 3) is somewhat smaller than that used by Cahn \& Kaler. Besides, the diameter measured in the light of [OIII] $5007 \AA$ and in B-system is smaller than that in $\mathrm{H} \alpha$, which can be explained by the stratification effect. A large nearly circular halo (Table 3 ) of about 50 arcsec has been found in $\mathrm{H} \alpha$.

\subsection{IC 4997 (PK $58-10.1)$}

In SECGPN under 058.3-10.9; optical diameter 1.6 arcsec from Cahn \& Kaler (1971). The measured nebular diameter (Table 3) of this standard object is again somewhat smaller than that given in the literature. 


\subsection{Possible nebulae}

On the frames the objects MWC 560, MWC 574, LS IV $12^{\circ} 111$ and HR Del are somewhat larger than the surrounding stars, but their nebulae, if any, are extremely small (and the errors large), so that they should be concidered as uncertain. The most promising of them is LS IV $-12^{\circ} 111$ with the smallest mean errors. As to HR Del the nebulosity in [OIII] $5007 \AA$ was already reported (see e.g. Kohoutek 1981). For the year 1995 the nebulosity was expected to be larger than that we observed, so that we think that our small values are either due to the low brightness of the nebula relative to the very bright star in the centre, or that we see only the brightest part of the nebula.

\section{General discussion and conclusions}

About half of the objects listed in Table 1 show neither small nebulosities (their images are comparable with those of stars), nor large envelopes. Around three objects small nebulosities and around the standard nebula $\mathrm{Hb} 6$ a halo were discovered. Besides, at four further emission-line objects the presence of very small nebulae is possible, but questionable.

The above method with the relation given in Sect. 3 requires nebulosities with Gauss profiles. This is of course not valid for large nebulae, but it may be accepted for very small nebulosities (in the range of 1 arcsec or below). Perhaps this is the reason why the somewhat larger standard nebulae $\mathrm{Hb} 6$ and IC 4997, with a ringlike structure, appear smaller when using the Gauss approximation.

\section{References}

Acker A., Marcout J., Ochsenbein F., Stenholm B., Tylenda R., Schohn C., 1992, The Strasbourg-ESO Catalogue of Galactic Planetary Nebulae, European Southern Observatory (SECGPN)

Allen D.A., 1984, Proc. ASA 5 (3), 369

Arhipova V.P., 1973, Perem. Zvezdy 19, 273

Cahn J.H., Kaler J.B., 1971, ApJS 189, 319

Kohoutek L., 1978, IAU Symp. No. 76. In Terzian Y. (ed.), p. 47 (Suppl. 1 to CGPN)

Kohoutek L., 1981, MNRAS 196, 87P

Kohoutek L., 1993, IAU Symp. No. 155. In Weinberger R., Acker A. (eds.) - poster; Astron. Nachr. 315 (1994), 63 (Suppl. 4 to CGPN)

Kohoutek L., 1995, Hydrogen-Deficient Stars, Colloquium in Bamberg, Germany, August/Sept. 1995 - poster = Proceedings. In Jeffery C.S., Heber U. (eds.), ASP Conf. Ser. 96, 219 (1996)

Kohoutek L., 1996, IAU Symp. No. 180 - poster (submitted to Astron. Nachr.) (Suppl. 5 to CGPN)

Perek L., Kohoutek L., 1967, Catalogue of Galactic Planetary Nebulae, Academia Praha (CGPN)

Roche P.F., Allen D.A., Baily J.A., 1986, MNRAS 220, 7P

Schwarz H.E., Corradi R.L.M., Melnick J., 1992, A\&AS 96, 23 